\title{
Cross-cultural comparison of growth, maturation and adiposity indices of two contrasting adolescent populations in rural Senegal (West Africa) and Martinique (Caribbean)
}

\author{
Eric Bénéfice* , Nathalie Caïus and Denis Garnier \\ Epidemiology and Prevention Research Unit (R024), Centre IRD (Institut de recherche pour le développement) \\ de Montpellier, 911 avenue Agropolis, BP 64501, F-34394 Montpellier, France
}

Submitted 30 July 2003: Accepted 2 0ctober 2003

\begin{abstract}
Objectives: To stress the importance of social and environment (nutritional) factors in determining the growth spurt during puberty and the risk of excessive adiposity, two contrasting adolescent populations, one from a rural area of Senegal (West Africa) and the other from Martinique (French West Indies), were compared.

Design: Cross-cultural comparison of contrasting populations. Adolescents from Senegal belonged to a cohort followed up since 1995. Adolescents from Martinique participated in a cross-sectional nutritional survey that covered the entire island.

Subjects: A total of 507 adolescents (mean age: $14.3 \pm 0.7$ years) from Senegal (319 girls and 188 boys) and 703 adolescents from Martinique (351 boys and 352 girls) were surveyed.

Results: Differences in growth and maturation were striking: boys in Martinique were $22.7 \mathrm{~kg}$ heavier and $20.1 \mathrm{~cm}$ taller than boys in Senegal. Differences were less important for girls but still evident: $12.6 \mathrm{~kg}$ in weight and $10.5 \mathrm{~cm}$ in stature. In Senegal, there were virtually no overweight adolescents, but $18 \%$ of girls and $50 \%$ of boys could be considered as malnourished. In Martinique, 19\% of girls and 23\% of boys were overweight or obese. Adolescent girls from Martinique were also sexually more mature than adolescent girls from Senegal. When comparisons were repeated after Senegalese girls reached menarche, differences in weight and body mass index disappeared, but Senegalese girls were still shorter than girls from Martinique.

Conclusions: Adolescents are extremely susceptible to nutritional changes and their particular situation needs to be incorporated into nutritional prevention programmes.
\end{abstract}

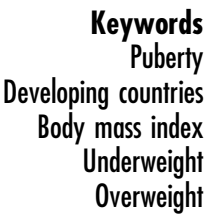

During adolescence, because of the growth spurt during puberty, size and body proportion change. Although boys and girls have quite similar fat mass during childhood, girls increase their fat mass during puberty while boys, in contrast, stabilise their fat mass and enlarge their fat-free mass ${ }^{1}$. As a consequence, it is risky to identify overweight and adiposity during adolescence on the basis of a composite index such as the body mass index (BMI; weight $/$ height $^{2}$ ) and a single set of references ${ }^{2}$. To interpret this index accurately, puberty maturation stage should be taken into account, although this is not always possible $^{3}$. Despite these limitations, the BMI is now widely accepted as the simplest index for comparison purposes in epidemiological studies ${ }^{4}$.

Familial and ethnic factors also need to be considered as important determinants of body composition. American adolescent girls of African origin tend to accumulate more fat after 12 years of age than do girls of European origin, although they are slimmer before this age ${ }^{5}$ A recent survey encompassing various populations from the
African Diaspora showed that the heritability of adiposity indices remained steady across a wide range of environments in genetically related populations ${ }^{6}$.

These considerations should be viewed in light of the context of the 'obesity epidemic' that is spreading on a world-wide scale ${ }^{7}$. It is estimated that, in the next few years, two-thirds of the morbidity burden will be linked to obesity-related diseases, even in less developed countries $^{8}$. Factors underlying this so-called 'nutritional transition' are now well identified in emerging countries of

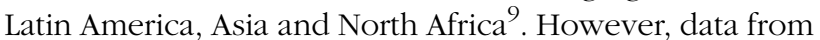
sub-Saharan Africa are more scanty, although recent papers indicate that the risk of obesity and obesity-related diseases is increasing ${ }^{2,10-12}$. But these rather limited data cannot be generalised at the scale of the entire continent: large areas of Africa still continue to suffer from malnutrition $^{13}$.

As a consequence, in Africa there are many uncertainties and unresolved questions. This is worrying because, in the next few years, implementation strategies and prevention 
programmes for fighting malnutrition and obesity are to be completely redefined ${ }^{8}$. Hence, the objective of the present paper is to compare data on the growth and maturation of Senegalese adolescents from a rural area, exposed to food insecurity, with similar data taken from adolescents from the French department of Martinique (Caribbean basin) who share with them a common African heritage.

\section{Methods}

\section{Design of the studies}

The Senegalese study

Adolescents studied here belonged to a cohort of children born in 1983-1984 and followed up yearly from 1995 to 2000 within the framework of a prospective study on puberty. All children originated from the Niakhar district of Senegal, a rural area located $150 \mathrm{~km}$ east of the capital, Dakar. This area presents a long dry season (NovemberJuly) and a short rainy season (August-October). The 30000 inhabitants subsist mainly on non-mechanised cultivation of millet and peanuts and on cattle herding. They belong to the Sereer ethnic group. Because of persistent drought during the past several decades, along with population growth and over-cultivation of the soil, a situation of food insecurity exists. While some improvements have occurred recently ${ }^{14}$, infant and under-five mortality rates (80 and 213 per 1000 , respectively) are excessive, and there is a high prevalence of malnutrition. According to the World Health Organization's (WHO) database (http://www.who.int/nutgrowthdb/), more than $25 \%$ of pre-school children are stunted and $7 \%$ are wasted. There is no regular school attendance: about $40-50 \%$ of children are enrolled in school, but only a small number of children successfully finish the first cycle.

All girls were part of an initial cohort of 406 adolescents. Measurements were performed in April 1998 when the girls were $14.3 \pm 0.5$ years old. Data from the April 2000 survey $(n=323)$, when they reached $16.5 \pm 0.6$ years, were also used. Boys were surveyed in March 2000: of a total of 3820 boys aged 10 to 17 years, 400 boys from all 30 villages in the area were chosen randomly. A total of 378 had complete measurements, and 188 boys between 12.5 and 16.5 years of age (mean: $14.4 \pm 1.1$ years) were included in this study.

The objective of the study was explained individually to adolescents and their parents. Religious and political leaders from the village were also informed. Because parents were generally illiterate, oral consent was requested. Examinations were conducted publicly by the authors of the paper. The protocol was approved by the joint Senegal Ministry of Research and the French Research Institute for Development (IRD).

\section{The Martinique study}

Martinique, a Caribbean island, is a French overseas department with a population of 381325 inhabitants (1999 census). The climate is tropical with a maritime influence. The economy is ruled by tertiary industries. The unemployment rate is high, $28 \%$, which is three times higher than in metropolitan France. The population has descended from lengthy crossbreeding between different migrant groups: African, Indians, Europeans and more recently Chinese and Syrians. The West African admixture is high. Since it is part of France, Martinique benefits from the same educational and health services. School attendance is compulsory until 16 years of age.

Our study included a representative sample of schoolchildren from the 4 th class of college (middle school, French system), corresponding to a theoretical age of 14 years. The sample included a homogeneous group from mid-puberty to the end of puberty. The total number of eligible school children was 6940. The sample was drawn using a PPS (probability proportional to size) sampling procedure to obtain a balanced representation of the entire island. For $5 \%$ precision, 768 children had to be included. A total of 993 children were drawn and 715 were examined $^{15}$. The main reason for missing data was the high absenteeism at the end of the academic year. A total of 703 adolescents were included in this study. Boys were aged $14.4 \pm 0.7$ years and girls, $14.3 \pm 0.7$ years.

The objective of the study was approved and authorized by the Recteur d'Académie (head of educational services) of Martinique and by school health authorities. Complete explanations were given to children and teachers, and written consent was requested of parents. Confidentiality of results was guaranteed. Examinations took place individually in medical rooms and were conducted by specialised nurses at the colleges.

\section{Food habits and physical activity patterns}

In Senegal, direct observations of physical activity and objective measurements of activity using accelerometers were carried out in sub-samples of children. During the visits, girls or boys were asked about their food habits and their food intakes during the past $24 \mathrm{~h}$. Food consumption of a sub-sample of girls was also investigated by a direct weighing method over four consecutive weekdays. The methodology used in this survey has been published previously $^{16}$. A synthesis of results will continually be given as background.

In Martinique, children had to fill out a questionnaire concerning their food consumption and physical activity habits. Nurses then checked the questionnaire in the presence of the child. From a food list, daily frequencies were recorded qualitatively ${ }^{15}$. Physical activity was recorded using a questionnaire derived from Baecke et $a{ }^{17}$.

\section{Growtb and puberty assessment}

Basic anthropometrics consisted of weight $(\mathrm{kg})$ measured with $100 \mathrm{~g}$ accuracy using an electronic scale and standing height $(\mathrm{cm})$. In Senegal, height was measured with 
a portable Harpenden ${ }^{\circledR}$ anthropometer. In Martinique height was measured with fixed stadiometers. Measurements were made with children barefoot and lightly clothed. In addition, in Martinique, waist and hip circumferences were taken with a non-stretchable tape. In Senegal, six subcutaneous skinfolds were measured to the nearest $0.2 \mathrm{~mm}$ using a Holtain ${ }^{\circledR}$ calliper: triceps, biceps, subscapular, supra-iliac, abdominal and medial calf. All measurements were taken on the sites according to standard techniques ${ }^{18}$. The following anthropometric indices were calculated: height-for-age and weight-forage, expressed in $Z$-scores of the WHO/National Center for Health Statistics (NCHS) reference population ${ }^{19}$. Overweight and obesity were assessed on the basis of BMI values as recommended by the International Obesity Task Force ${ }^{20}$. Sex- and age-specific cut-off points that would correspond to a BMI of $25 \mathrm{~kg} \mathrm{~m}^{-2}$ (overweight) and $30 \mathrm{~kg} \mathrm{~m}^{-2}$ (obesity) at 18 years of age were chosen ${ }^{21}$. BMI was also used to determine specific age and sex cut-off points for moderate $(<5$ th percentile) and light $(<15$ th percentile) malnutrition using the NCHS reference data ${ }^{22}$.

In Senegal, sexual maturity of the girls was determined according to stage of breast development ${ }^{23}$. Adolescent girls were also asked about the occurrence or not of menstruation. If the girl did not understand, her mother was asked instead. For Senegalese boys, circumstances did not allow us to examine their sexual maturity closely and thus this information was not obtained. In Martinique, nurses asked the girls for the date of their first menstruation and questioned the boys about the onset of a clear change in pitch of their voice.

\section{Results}

\section{Summary of adolescent food habits and activities}

The Senegalese study

From the quantitative survey performed in a sub-sample of 40 adolescent girls, it was estimated that their mean daily energy intake was $2681 \pm 795 \mathrm{kcal}$ for a calculated requirement of $2398 \mathrm{kcal}$, according to their activity level, age and weight ${ }^{24}$. Thus, with an adequacy of $113 \%$, adolescents apparently met their energetic needs. However, there were great disparities between households. Energy intakes came principally from cereals (mainly millet or sorghum and rice). Animal products were rarely consumed: less than $63 \mathrm{~g}$ of meat or fish per day (generally dry fish). Lipids were almost exclusively represented by vegetable sources, mostly peanuts present in many sauces. As a whole, lipids brought only $20 \%$ of total energy. Wide seasonal fluctuations existed and, at the end of the dry season, lunch was frequently skipped. These values represent only median figures.

The physical activity of Senegalese adolescents estimated by an objective accelerometry method during several rounds was considered to be high ${ }^{24}$, falling into the 'heavy' category (physical activity level $\geq 1.85$ multiples of basal metabolic rate) suggested by the recent Food and Agriculture Organization/WHO/United Nations University joint committee ${ }^{25}$. In boys, high levels of activity were observed during leisure time. Boys also participated in agricultural tasks: they were in charge of herding and helping their fathers in clearing and hoeing the fields. On average, herding and farming occupied about $25 \%$ of their daytime activities. Girls were far less involved in agricultural activities (5\%) but had to help their mothers at home ${ }^{16}$.

\section{The Martinique study}

Adolescents had three main meals during the day plus two snacks. Interestingly, about $10 \%$ of the children did not have breakfast in the morning. Food items varied, with regular consumption of pasta, rice and meat on a daily basis. Milk products were consumed at least twice a day; fish was present less often. Vegetables and lettuces, red kidney beans and lentils were eaten on a regular basis. Local vegetables and tubers were consumed at least once a week by a majority of the children. Consumption of sweet drinks and fruit juice was high.

Apart from compulsory hours of physical training during school hours, most children took part in at least one sport. This was the case for $80 \%$ of the boys and $53 \%$ of the girls. Half of the boys trained on a regular basis, spending about $5 \mathrm{~h}$ per week in sports compared with less than $3 \mathrm{~h}$ for girls. Television (TV) viewing and video games were the most frequent leisure activities, cited by $70 \%$ of the adolescents. Girls watched TV for a longer period than boys. Working and helping parents in energy-demanding tasks was only occasional.

\section{Maturation and growth}

At 14 years of age, the difference in sexual maturation between girls from Senegal and Martinique was striking: while 333 girls out of 352 (94.6\%) had already experienced menarche in Martinique, only 39 out of 319 (12.2\%) were menstruating in Senegal. According to their breast development, $12.2 \%$ of the Senegalese girls were at stage 1 (pre-pubescent); most (56.2\%) were at stages 2 and 3 (mid-puberty); and only $8.1 \%$ had completed puberty. In Martinique, the mean age of menarche in menstruating girls was $11.9 \pm 1.1$ years (median: 12.0 years). In Senegal, there were no objective measurements of pubertal status for boys, although subjectively they all presented an immature appearance. In Martinique $75 \%$ of boys showed a voice change at a mean age of $13.0 \pm 1.0$ years.

Differences in body size were also very pronounced (Table 1). There were no significant differences in age according to origin for boys as well as girls. Adolescents from Martinique were considerably taller and stronger than those from Senegal. Senegalese adolescent boys were shorter by $20.1 \mathrm{~cm}$ and girls by $10.5 \mathrm{~cm}$ compared with those from Martinique. It is thus possible that most of the 
Table 1 Anthropometric differences between adolescents from Senegal and Martinique

\begin{tabular}{|c|c|c|c|c|c|c|c|}
\hline & \multicolumn{2}{|c|}{ Martinique } & \multicolumn{2}{|c|}{ Senegal } & \multirow[b]{2}{*}{ Difference } & \multirow[b]{2}{*}{$t$} & \multirow[b]{2}{*}{$P$-value } \\
\hline & Mean & SD & Mean & SD & & & \\
\hline Boys & \multicolumn{2}{|c|}{$(n=351)$} & \multicolumn{2}{|c|}{$(n=188)$} & & & \\
\hline Age (years) & 14.4 & 0.7 & 14.4 & 1.1 & 0.04 & 0.5 & NS \\
\hline Weight (kg) & 59.5 & 14.7 & 36.7 & 7.0 & 22.7 & 20.0 & 0.0001 \\
\hline Height (cm) & 169.2 & 8.9 & 149.0 & 10.2 & 20.1 & 23.6 & 0.0001 \\
\hline HAŽ & 0.46 & 1.01 & -2.01 & 1.09 & 2.4 & 26.3 & 0.0001 \\
\hline WAZ & 0.41 & 1.26 & -2.02 & 0.73 & 2.4 & 24.6 & 0.0001 \\
\hline BMI $\left(\mathrm{kg} \mathrm{m}^{-2}\right)$ & 20.6 & 3.9 & 16.3 & 1.4 & 4.2 & 14.1 & 0.0001 \\
\hline Waist/hip ratio & 0.83 & 0.07 & - & - & - & - & - \\
\hline Sum of six skinfolds & - & - & 31.6 & 6.7 & - & - & - \\
\hline Trunk/extremity* & - & - & 0.90 & 0.14 & & & \\
\hline Girls & \multicolumn{2}{|c|}{$(n=352)$} & \multicolumn{2}{|c|}{$(n=319)$} & & & \\
\hline Age (years) & 14.29 & 0.68 & 14.34 & 0.55 & 0.04 & 0.9 & NS \\
\hline Weight (kg) & 54.7 & 12.2 & 42.0 & 7.9 & 12.6 & 15.9 & 0.0001 \\
\hline Height $(\mathrm{cm})$ & 162.6 & 6.4 & 152.1 & 7.4 & 10.5 & 19.6 & 0.0001 \\
\hline HAZ & 0.30 & 0.97 & -1.29 & 1.08 & 1.59 & 20.0 & 0.0001 \\
\hline WAZ & 0.17 & 1.09 & -1.19 & 0.89 & 1.36 & 17.5 & 0.0001 \\
\hline $\mathrm{BMI}\left(\mathrm{kg} \mathrm{m}^{-2}\right)$ & 20.5 & 4.1 & 18.0 & 2.4 & 2.5 & 9.6 & 0.0001 \\
\hline Waist/hip ratio & 0.79 & 0.08 & - & - & - & - & - \\
\hline Sum of six skinfolds & - & - & 60.0 & 25.2 & - & - & - \\
\hline Trunk/extremity & - & - & 0.83 & 0.16 & - & - & - \\
\hline
\end{tabular}

SD - standard deviation; HAZ - height-for-age Z-score; WAZ - weight-for-age Z-score; BMI - body mass index; NS - not significant.

${ }^{*}$ Trunk/extremity - ratio of trunk to extremity, i.e. (subscapular + supra-iliac + abdominal)/(triceps + biceps + medial calf) skinfolds.

differences in body mass were actually due to the difference in stature. After adjusting for stature by covariance analysis, differences still persisted in boys (Martinique: $53.4 \pm 9.5 \mathrm{~kg}$ vs. Senegal: $48.0 \pm 9.6 \mathrm{~kg}$, $P<0.0001$ ) and girls (Martinique: $50.6 \pm 8.8 \mathrm{~kg}$ vs. Senegal: $46.3 \pm 8.7 \mathrm{~kg}, P<0.0001)$, although to a lesser extent. As indicated by $Z$-scores of height and weight, in comparison with the international reference, Senegalese adolescents presented an important delay that was more pronounced in boys than in girls. In contrast, adolescents from Martinique were slightly advanced.

The between-country difference in BMI was $4.2 \mathrm{~kg} \mathrm{~m}^{-2}$ in boys and $2.5 \mathrm{~kg} \mathrm{~m}^{-2}$ in girls, thus radically determining different patterns of over- or underweight, as seen in Table 2. In Martinique, almost $20 \%$ of girls and $25 \%$ of boys were overweight or overtly obese whereas, in Senegal, only five girls and no boys were overweight. Figures were the opposite for underweight: nearly half of Senegalese boys could be considered as malnourished. Nutritional

Table 2 Comparison of prevalence rate (\%) of overweight, obesity and underweight between adolescents from Senegal and Martinique

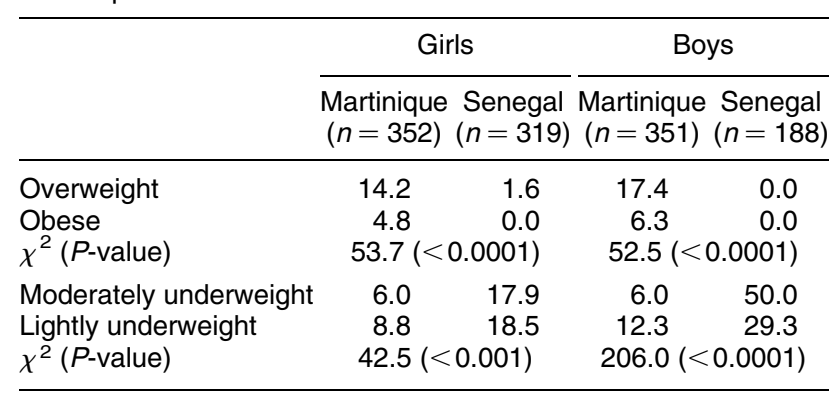

status was better for girls. Regional fat distribution also differed between the groups. In Martinique, values of the waist/hip ratio were slightly above the median of a French population of the same age and $\operatorname{sex}^{26}$, indicating a trend to an abdominal deposition of fat. The sums of six skinfolds in Senegalese boys were well below values observed in French Canadians $(>47 \mathrm{~mm}$ ), but roughly the same for girls $(65 \mathrm{~mm})^{26}$. Ratios of trunk to extremity skinfolds were below those of Canadian adolescents ${ }^{26}$ in boys as well as in girls, implying more deposition of fat in the limbs than in the trunk.

As these differences could be partly explained by disparities in the tempo of growth during puberty, it was interesting to perform comparisons after adjustment for maturation status. Such comparisons were possible in the case of Senegalese girls because they were seen again 2 years later, in April 2000. By that time, 67\% of them had experienced menarche. Comparisons of anthropometric measurements after the occurrence of menarche are presented in Table 3: differences no longer existed in weight and BMI but persisted for height.

\section{Discussion}

The adolescents studied here presented striking differences in growth and maturation status, although they belonged to the same age cohort. Such differences were expected, since the two settings represented clearly distinct economic and social systems. But there also existed some similarities that made comparisons interesting. Both settings were former French colonies devoted to the production of one specific agricultural product: 
Table 3 Comparison of anthropometric indices between adolescent girls from Senegal and Martinique after occurrence of menarche

\begin{tabular}{|c|c|c|c|c|c|c|c|}
\hline & \multicolumn{2}{|c|}{ Martinique $(n=333)$} & \multicolumn{2}{|c|}{ Senegal $(n=216)$} & \multirow[b]{2}{*}{ Difference } & \multirow[b]{2}{*}{$t$} & \multirow[b]{2}{*}{$P$-value } \\
\hline & Mean & SD & Mean & SD & & & \\
\hline Age (years) & 14.3 & 0.7 & 16.6 & 0.6 & 2.3 & 38.7 & 0.001 \\
\hline Weight (kg) & 55.0 & 12.1 & 54.3 & 7.5 & 0.8 & 0.8 & NS \\
\hline Height (kg) & 162.7 & 6.3 & 160.4 & 5.9 & 2.3 & 4.3 & 0.001 \\
\hline HAZ & 0.31 & 0.96 & -0.37 & 0.92 & 0.69 & 8.3 & 0.001 \\
\hline WAZ & 0.21 & 1.07 & -0.37 & 0.80 & 0.58 & 6.8 & 0.001 \\
\hline BMI $\left(\mathrm{kg} \mathrm{m}^{-2}\right)$ & 20.7 & 4.1 & 21.1 & 2.7 & 0.3 & 1.1 & NS \\
\hline
\end{tabular}

SD - standard deviation; HAZ - height-for-age Z-score; WAZ - weight-for-age Z-score; BMI - body mass index; NS - not significant.

peanuts for oil in the case of Senegal, and cane sugar in Martinique. It is obvious that an important segment of the Martinique population is of African descent. Populations were taken from West Africa up to the beginning of the nineteenth century to work as slaves in Caribbean plantations. About 95\% of the present population result from crossbreeding between European, African and more recently East Indian groups. A recent analysis of names from official records reveals the importance of the African (especially West African) origin ${ }^{27}$. However, it is not possible to know precisely the degree of admixture in Martinique. The influence of the genetic background of these populations on the results could therefore not be disregarded. However, for the purpose of this study, we do consider that such an effect is weak with respect to the stronger environmental and nutritional influences.

Between-group differences in growth are clearly linked to the maturation tempo. In Senegal, using a probit procedure, a median age at menarche of 16.1 years (confidence interval: 15.8-16.4) was reported in a sample of adolescents from the same area ${ }^{28}$. This should be compared with the mean age of $11.9 \pm 1.1$ years in Martinique, suggesting a 4-year difference in sexual maturation between groups. Although no indicators of maturation were obtained from Senegalese boys, the fact that they were shorter than girls at 14 years of age (a difference of $>4 \mathrm{~cm}$ ) suggests that their puberty growth spurt was significantly delayed. The height deficit of boys with respect to girls was not recovered until 16-17 years of age $^{28}$. The opposite was seen in Martinique, where, at the same age of 14 years, boys were about $7 \mathrm{~cm}$ taller than girls. Deficits in maturation and growth were greater in Senegalese boys than in girls, a fact already described in other African studies and which suggests greater nutritional vulnerability in boys than in girls ${ }^{29}$. In comparison with adult values from the same area ${ }^{30}$, it should be observed that the adolescents studied here lagged well behind (adult women: height $161.4 \pm 6.0 \mathrm{~cm}$, weight $56.3 \pm 7.0 \mathrm{~kg}$ at a mean age of $29.6 \pm 7.1$ years; adult men: height $174.4 \pm 7.6 \mathrm{~cm}$, weight $65.4 \pm 9.0 \mathrm{~kg}$ at a mean age of $38.4 \pm 10.8$ years). This strongly suggests that these adolescents were far from completing their physical growth.
An association between late maturation and nutritional status was observed some time ago $^{31}$. Whatever the reasons and underlying theories, such differences were also described in Africa between urban (well-nourished) and rural (malnourished) adolescent girls ${ }^{29}$. Interestingly, in Dakar, the capital city of Senegal, a mean age at menarche of $14.0 \pm 0.5$ years was reported from a sample of 722 girls belonging to the median stratum of society $^{32}$. The latter figure conforms with age at menarche in Africa reported in other studies ${ }^{33,34}$, denoting a dramatic delay in maturation in the girls studied here, even by local standards. By comparison with adolescent girls of rural origin studied in Kenya, these Senegalese girls appeared to be less severely stunted and wasted, although they showed a longer delay in menarche (15.3 vs. 16.1 years $)^{28,29}$. Thus, nutritional factors are not the sole explanation for delays in the occurrence of menarche. Indeed, it is interesting to note that girls from Martinique were heavier than Senegalese girls at 14 years of age, but this advance disappeared when the latter reached menarche. While it is clear that Senegalese girls did not fully catch up in growth after menarche, some recuperation did occur. The maintenance of prolonged growth velocity after menarche would result in fairly complete recovery ${ }^{28}$. Likewise, the severe immaturity of Senegalese boys carries a real risk of misclassification and of overestimation of the prevalence of malnutrition.

In contrast with Senegal, the situation in Martinique was quite different. Adolescents presented an advance in maturity with respect to a national sample from metropolitan France ${ }^{35}$. Median age at menarche was estimated as 12.0 years in Martinique ${ }^{15}$ compared with a median age of 13.1 years in metropolitan France; and 13.0 years for a change of voice in Martinique compared with a median age of 14.8 years in France. Such advances are in agreement with reports in industrialised countries concerning adolescents of African and Caribbean origin ${ }^{36,37}$. Earlier maturation is also correlated with greater fat deposition during puberty ${ }^{37}$. Adolescents from Martinique had relatively high waist/hip ratios, denoting a tendency for central deposition of fat. Such a pattern is known to be associated with a higher risk of metabolic diseases in the 
Caribbean islands ${ }^{38}$. In contrast, Senegalese adolescents had higher limb than trunk fat deposition.

Overweight and obesity were found to be very common in Martinique, and involved 20 to $24 \%$ of the sample. Such a trend in the increase of obesity also affects Latin America and the Caribbean basin ${ }^{39,40}$. It is matched by changes in the nature of foods consumed and in the total amount of energy ingested ${ }^{41}$. In contrast, Senegalese adolescents were free of excessive adiposity. This does not mean that the risk is non-existent in other parts of the country, especially in cities ${ }^{10}$, but as shown in a recent African study, excessive adiposity accretion is generally observed after the first menstruation and is mainly a post-menarcheal phenomenon ${ }^{33}$. Since Senegalese girls caught up in weight rather than in height after reaching menarche (Table 3), this could well be the case here.

Physical activity could also be an important determinant of differences in nutritional status. Objective field surveys performed in the same cohort indicated high levels of habitual activity (25\% of their day was spent in moderate or vigorous activities for girls ${ }^{24}$, and $37 \%$ for boys ${ }^{42}$ ). Although no objective comparison was practicable from our data, it is likely that such levels exceeded those of adolescents in Martinique. The equilibrium between food consumption and energy balance is of importance. Energy amount is adequate in Senegal during part of the year, but undergoes seasonal fluctuations that result in household food insecurity ${ }^{30}$. The adolescent Senegalese diet was mainly vegetarian: food intakes from animals (fish or milk) were very limited. Virtually no animal fat was eaten. Such a diet can induce severe deficiencies in minerals and vitamins (the low intakes of iron, calcium and retinol are of particular concern). In comparison, adolescents from Martinique were not quantitatively limited and tended to rely principally on industrial and refined products. Physical activity and food consumption pattern discrepancies between the two groups no doubt accounted for most of the observed differences in growth and maturation.

Finally, both groups diverged markedly from the present scheme of nutritional transition and of obesity epidemic. In the developing world, the changes in food and activity patterns are occurring at a faster rate than those observed previously in the industrialised world ${ }^{43}$. Moreover, in Latin America and the Caribbean, no concurrent reduction in chronic malnutrition and the prevalence of stunting has taken place ${ }^{40}$. This is not the case in Martinique, where adolescents surpass the international reference in size. In contrast, rural populations in Senegal continue to display a slow tempo of puberty and growth characterising chronic malnutrition. The pattern of growth during adolescence could thus constitute an accurate gauge for comparing the nutritional status of populations. Reported differences represent a biological measurement of the gap between the First and the Third Worlds and between privileged and underprivileged classes of society within the same country.

Adolescence is a period of transition wherein childhood traits such as malnutrition and growth retardation continue to be expressed, but where the trend towards excessive adiposity in adulthood may also begin to be manifested ${ }^{44}$. This period is also much more receptive to nutritional intervention and prevention programmes than is adulthood. In girls, adolescence takes on a special significance because it marks the entry into the reproductive life cycle. For all of these reasons, adolescence should be better integrated into nutritional and health programmes by policy planners.

\section{Acknowledgements}

In Senegal, many thanks go to Tofene Ndiaye and Amady Ndiaye who worked as supervisors. Thanks are also extended to Frederique Vanacker and Gnagna Ndiaye who participated in the study as graduate students, and to Etienne Ndong, Moussa Sarr and the local surveyors. In Martinique, the study was made possible by the assistance of Dr Bottius and Mme Casca, chiefs of the health service of the Martinique Rectorat, and by the co-operation of all the principals and nurses of secondary schools. The authors especially thank Dr Merle, responsible for the Regional Health Observatory Bureau, for her kind cooperation. M Barreteau, who was in charge of IRD-La Martinique, provided support and encouragement to the team during the survey. We are especially indebted to all adolescents and families from Senegal and Martinique, who kindly agreed to participate in the survey.

The project was supported financially by the R024 Research Unit of the IRD and in part by a grant from the Nestlé Foundation.

\section{References}

1 Rogol AD, Roemmich JN, Clark PA. Growth at puberty. Journal of Adolescent Health 2002; 31: 192-200.

2 De Onis M, Blossner M. Prevalence and trends of overweight among preschool children in developing countries. American Journal of Clinical Nutrition 2000; 72: 1032-9.

3 Woodruff BA, Duffield A. Anthropometric assessment of nutritional status in adolescent populations in humanitarian emergencies. European Journal of Clinical Nutrition 2002; 56: $1108-18$.

4 Bellizzi MC, Dietz WH. Workshop on childhood obesity: summary of the discussion. American Journal of Clinical Nutrition 1999; 70: 173S-5S.

5 Kimm SY, Barton BA, Obarzanek E, McMahon RP, Sabry ZI, Waclawiw MA, et al. Racial divergence in adiposity during adolescence: The NHLBI Growth and Health Study. Pediatrics 2001; 107: E34.

6 Luke A, Guo X, Adeyemo AA, Wilks R, Forrester T, Lowe W $\mathrm{Jr}$, et al. Heritability of obesity-related traits among Nigerians, Jamaicans and US black people. International Journal of Obesity and Related Metabolic Disorders 2001; 25: 1034-41. 
7 Seidell JC. Obesity: a growing problem. Acta Paediatrica Supplement 1999; 88: 46-50.

8 Chopra M, Galbraith S, Darnton-Hill I. A global response to a global problem: the epidemic of overnutrition. Bulletin of the World Health Organization 2002; 80: 952-8.

9 Popkin BM. An overview on the nutrition transition and its health implications: the Bellagio meeting. Public Health Nutrition 2002; 5: 93-103.

10 Maire B, Delpeuch F, Cornu A, Tchibandat F, Simondon F, Massamba JP, et al. [Urbanization and nutritional transition in sub-saharan Africa: exemplified by Congo and Senegal]. Revue d'Epidemiologie et de Santé Publique 1992; 40: 252-8.

11 Ansa VO, Odigwe CO, Anah MU. Profile of body mass index and obesity in Nigerian children and adolescents. Nigerian Journal of Medicine 2001; 10: 78-80.

12 Maletnlema TN. A Tanzanian perspective on the nutrition transition and its implications for health. Public Health Nutrition 2002; 5: 163-8.

13 De Onis M, Frongillo EA, Blossner M. Is malnutrition declining? An analysis of changes in levels of child malnutrition since 1980. Bulletin of the World Health Organization 2000; 78: 1222-33.

14 Delaunay V, Etard JF, Preziosi MP, Marra A, Simondon F. Decline of infant and child mortality rates in rural Senegal over a 37-year period (1963-1999). International Journal of Epidemiology 2001; 30: 1286-93, discussion 1294-5.

15 Caius N, Benefice E. [Food habits, physical activity and overweight among adolescents]. Revue d'Epidemiologie et de Santé Publique 2002; 50: 531-42.

16 Benefice E, Cames C. Physical activity patterns of rural Senegalese adolescent girls during the dry and rainy seasons measured by movement registration and direct observation methods. European Journal of Clinical Nutrition 1999; 53: 636-43.

17 Baecke J, Burema J, Frijters J. A short questionnaire for the measurement of habitual physical activity in epidemiological studies. American Journal of Clinical Nutrition 1982; 36: 936-42.

18 Lohman TG, Roche A, Martorell R. Antbropometric Standardization Reference Manual. Champaign, IL: Human Kinetics Books, 1988.

19 World Health Organization Working Group. Use and interpretation of anthropometric indicators of nutritional status. Bulletin of the World Health Organization 1986; 64: 929-41.

20 Dietz WH, Bellizzi MC. Introduction: the use of body mass index to assess obesity in children. American Journal of Clinical Nutrition 1999; 70: 123S-5S.

21 Cole TJ, Bellizzi MC, Flegal KM, Dietz WH. Establishing a standard definition for child overweight and obesity worldwide: international survey. British Medical Journal 2000; 320: 1240-3.

22 Must A, Dallal G, Dietz W. Reference data for obesity: 85 th and 95 th percentiles of body mass index $\left(\mathrm{W} / \mathrm{ht}^{2}\right)_{-}^{-}$ a correction. American Journal of Clinical Nutrition 1991; 54: 773 .

23 Tanner J. Growth at Adolescence, 2nd ed. Oxford: Blackwell Scientific, 1962

24 Benefice E, Garnier D, Ndiaye G. High levels of habitual physical activity in west African adolescent girls and relationship to maturation, growth, and nutritional status: results from a 3-year prospective study. American Journal of Human Biology 2001; 13: 808-20.

25 Torun B. Significance of habitual physical activity in formulating dietary energy recommendations for children and adults. Food, Nutrition and Agriculture 2002; 30: 31-40.
26 Malina R. Regional body composition: age, sex, and ethnic variation. In: Roche A, Heymsfield S, Lohman T, eds. Human Body Composition. Champaign, IL: Human Kinetics, 1996; $217-55$.

27 Durand G. The survival of African names in Martinique after emancipation. Dialectal Anthropology 2001; 26: 193-233.

28 Simondon K, Simon I, Simondon F. Nutritional status and age at menarche of Senegalese adolescents. Annals of Human Biology 1997; 6: 521-32.

29 Kulin HE, Bwibo N, Mutie D, Santner S. The effect of chronic childhood malnutrition on pubertal growth and development. American Journal of Clinical Nutrition 1982; 36: 527-36.

30 Simondon K, Benefice E, Simondon F, Delaunay V, Chahnazarian A. Seasonal variation in nutritional status of adults and children in rural Senegal. In: Ulijaszek S, Strickland S, eds. Seasonality and Human Ecology. Cambridge: Cambridge University Press, 1993; 166-83.

31 Dreizen S, Spirakis C, Stone R. A comparison of skeletal growth and maturation in undernourished and wellnourished girls before and after menarche. Journal of Pediatrics 1967; 70: 256-63.

32 Sarr M, Tal-Dia A, Signaté-Sy H, Diouf S, Moreira C, Diagne I, et al. [Clinical study of growth and puberty in girls in a school environment in Dakar. Survey on 722 cases]. Archives de Pediatrie 1998; 5: 809-13.

33 Cameron N, Getz B. Sex differences in the prevalence of obesity in rural African adolescents. International Journal of Obesity and Related Metabolic Disorders 1997; 21: 775-82.

34 Thomas F, Renaud F, Benefice E, de Meeus T, Guegan JF. International variability of ages at menarche and menopause: patterns and main determinants. Human Biology 2001; 73: 271-90.

35 De la Rochebrochard E. Les âges à la puberté des filles et des garçons en France. Population 1999; 54: 933-62.

36 Ulijaszek SJ, Evans E, Miller DS. Age at menarche of European, Afro-Caribbean and Indo-Pakistani schoolgirls living in London. Annals of Human Biology 1991; 18: $167-75$.

37 Anderson SE, Dallal GE, Must A. Relative weight and race influence average age at menarche: results from two nationally representative surveys of US girls studied 25 years apart. Pediatrics 2003; 111: 844-50.

38 Foucan L, Hanley J, Deloumeaux J, Suissa S. Body mass index (BMI) and waist circumference (WC) as screening tools for cardiovascular risk factors in Guadeloupean women. Journal of Clinical Epidemiology 2002; 55: 990-6.

39 Gulliford MC, Mahabir D, Rocke B, Chinn S, Rona R. Overweight, obesity and skinfold thicknesses of children of African or Indian descent in Trinidad and Tobago. International Journal of Epidemiology 2001; 30: 989-98.

40 Martorell R, Khan L, Hughes M, Grummer-Strawn L. Obesity in Latin American women and children. Journal of Nutrition 1998; 128: 1464-73.

41 Sinha D. Changing pattern of food, nutrition and health in the Caribbean. Nutrition Research 1995; 15: 899-938.

42 Vanacker F. Etude de la croissance, de la consommation alimentaire et de l'activité physique d'adolescents sénégalais en milieu rural. Nutrition et Alimentation. Montpellier: Université des Sciences et Techniques du Languedoc, 2000; 82.

43 Popkin BM. The shift in stages of the nutrition transition in the developing world differs from past experiences! Public Health Nutrition 2002; 5: 205-14.

44 Schneider D. International trends in adolescent nutrition. Social Science \& Medicine 2000; 51: 955-67. 